\title{
The effects of chronic carbon monoxide treatment on diet- induced obesity and Rev-erb-alpha target gene expression in adipose tissue
}

\author{
Tim Brodsky, Ryan McLoughlin, Ben Sell, and Thomas H. Reynolds IV* \\ Department of Health and Exercise Sciences, Skidmore College, USA
}

\begin{abstract}
The present study determined if carbon monoxide (CO) treatment reversed diet-induced obesity and insulin resistance. Because CO is a potential ligand for the nuclear receptor Rev-erb- $\alpha$, we also determined if CO treatment altered the mRNA expression of Rev-erb- $\alpha$ targets. Mice were fed a low fat diet (LFD) or a high fat diet (HFD) for 150 days. Following 110 days of the dietary intervention the HFD-fed mice were assigned to a CO inhalation group or a control group. The HFD-CO group was exposed to $250 \mathrm{ppm} \mathrm{CO}$ for one hour per day for 40 consecutive days. Body weight and edpididymal white adipose tissue (EWAT) mass were significantly elevated in HFD and HFD-CO mice compared to LFD mice, but no differences existed between HFD and HFD-CO mice. Area under the insulin-assisted glucose tolerance curve was significantly elevated in HFD and HFD-CO mice compared to LFD mice, but no differences existed between HFD and HFD-CO mice. Heme oxygenase-1 (HO-1) mRNA was significantly higher in EWAT of HFD-CO compared to HFD mice, indicating effective delivery of CO to adipose tissue. CO treatment did not alter Rev-erb- $\alpha$ expression or Rev-erb- $\alpha$ targets. These results indicate that $\mathrm{CO}$ inhalation does not attenuate diet-induced obesity/insulin resistance.
\end{abstract}

\section{Introduction}

Obesity is an increasingly prevalent metabolic disease that affects more than one third of United States adults [1]. Obesity is associated with insulin resistance and increases the risk of developing type 2 diabetes, a disease that results in an estimated $\$ 245$ billion in total healthcare costs [2]. Despite the prevalence and health risks associated with obesity, there are few viable and effective treatment options. Therefore, the development of new interventions that can promote weight loss and improve insulin sensitivity are paramount to reducing the prevalence of obesity and its associated diseases.

Recent studies demonstrate that increasing heme oxygenase-1 (HO-1) expression can reduce adiposity and heighten insulin sensitivity [3-6]. Although HO-1 induction by porphyrin molecules or genetic manipulations can improve obesity and insulin resistance, the cellular mechanism responsible for these changes remains to be established. One hypothesis is that the products of HO-1 enzyme activity, $\mathrm{CO}$ and biliverdin, exert the metabolically beneficial effects. CO has been shown to reduce inflammatory markers in both cultured cells and mice [7] and a novel CO releasing molecule can attenuate weight gain and preserve insulin sensitivity when mice are placed on a HFD [8]. However, whether or not $\mathrm{CO}$ alone can reverse already established obesity and insulin resistance is not established, although a recent study indicates that $\mathrm{CO}$ inhalation produces transient reduction in body fat of obese mice [9]. Further, the mechanism by which $\mathrm{CO}$ might promote weight loss and improve insulin sensitivity are not known. Establishing the efficacy of CO inhalation to reduce adiposity as well as identifying the mechanism of $\mathrm{CO}$ action may lead to novel interventions to combat obesity and type 2 diabetes.

CO may bind to the nuclear receptor Rev-erb- $\alpha$ [10]. Rev-erb- $\alpha$ is a ligand regulated transcription factor that acts as a transcriptional repressor [11,12] regulating circadian rhythms and metabolism $[13,14]$. Although heme has been identified as the ligand for Rev-erb- $\alpha[15,16]$, evidence suggests the Drosophila orthologue to Rev-erb- $\alpha$ binds CO and represses gene expression [10]. Whether or not the expression of Rev-erb- $\alpha$ targets is altered in tissues following CO treatment is not known, although a Rev-erb agonist has been shown to promote weight loss and suppress PGC-1 $\alpha$ mRNA expression, an established target of Rev-erb- $\alpha$ [14].

The purpose of the present study was to determine if CO treatment could reverse obesity and improve insulin resistance due to a high fat diet (HFD) in a manner that was associated with changes in the mRNA expression of well-established Rev-erb- $\alpha$ targets in white adipose tissue. We hypothesized that daily CO treatments would reduce adiposity and improve insulin action in mice with established diet-induced obesity. We also hypothesized that mRNA expression of the Rev-erb- $\alpha$ targets PGC- $1 \alpha$, PPAR $\gamma$, Bmall, and Rev-erb- $\alpha$ itself would be reduced by CO treatment.

\section{Methods}

\section{Treatment of animals}

Wildtype C57B6 male mice were purchased from the Jackson

Correspondence to: Thomas H. Reynolds IV, Ph.D., Department of Health and Exercise Sciences, Skidmore College, 815 North Broadway, Saratoga Springs, NY 12866, USA, Tel: (518) 580-8349, Fax: (518) 580-8356; E-mail: treynold@skidmore.edu

Key words: insulin, obesity, rev-erb, carbon monoxide, diabetes

Received: April 17, 2016; Accepted: May 28, 2016; Published: May 31, 2016 
Laboratory (Bar Harbor, ME). Upon arrival to the animal facility at Skidmore College, all mice ( 4-6 weeks old) were housed individually with cage enrichment nest-lets and fed ad libitum chow and water for one week. Mice were then randomly assigned to either a HFD (Test Diets, Catalog \#1810251, 60\% kcal from fat) or a low fat diet (LFD) (Test Diets, Catalog \#58145, 12\% kcal from fat). Following 15 weeks of the dietary intervention, HFD-fed mice were body weight-matched-assigned to a CO treatment group (HFD-CO) or control group. Mice from the HFD$\mathrm{CO}$ group were place in individual induction chambers where they received $\mathrm{CO}$ gas $(250 \mathrm{ppm}$ ) for $60 \mathrm{~min}$ per day for 40 consecutive days $[17,18]$. This CO concentration is slightly higher than what has been show to increase carboxyhemoglobin levels [9]. Induction chamber $\mathrm{CO}$ levels were confirmed by a CO monitor. Control mice from the HFD and LFD groups were placed in the induction chamber for $5 \mathrm{~min}$ daily and received air. During the intervention mice were maintained on their HFD or LFD. All animal care and surgery were conducted in accordance with the National Research Council's Guide for Care and Use of Laboratory Animals (Institute of Laboratory Animal Resources, Commission on Life Sciences, 1996). All experimental protocols were approved by Skidmore College's Institutional Animal Care and Use Committee.

\section{In vivo insulin action}

To assess the effects of a HFD and CO treatment on in vivo insulin action, mice were subjected to an insulin-assisted glucose tolerance (IAGT) test. Prior to the IAGT test mice were fasted overnight. Following the overnight fast, mice were simultaneously administered glucose ( $2 \mathrm{~g} / \mathrm{Kg}$ body weight) and insulin ( $2 \mathrm{U} / \mathrm{Kg}$ body weight) via intraperitoneal injection. Glucose was measured by a glucometer (ACCU-CHEK Aviva, Roche Diagnostics) in blood collected via the tail vein at $0,20,40$, and $60 \mathrm{~min}$ following the glucose/insulin injection. We have previously shown that the IAGT test detects insulin resistance as well as an insulin tolerance test in mice fed a HFD, but avoids the severe hypoglycemia that is typically observed during and after insulin tolerance testing [19].

\section{Surgical procedures}

Prior to harvesting tissues, mice were fasted overnight and then anesthetized with a 1:1:1 mixture of promace, ketamine hydrochloride, and xylazine by an intraperitoneal injection $(0.015 \mathrm{ml} / 10 \mathrm{~g}$ body weight). Epididymal white adipose tissue (EWAT) was rapidly dissected, frozen in liquid nitrogen, and stored at $-80^{\circ} \mathrm{C}$ until analysis.

\section{EWAT RNA extraction and real time quantitative PCR}

Total RNA was extracted from EWAT using RNA extraction kits for high lipid content tissue (Qiagen). RNA was quantified by measuring absorbance at $260 \mathrm{~nm}$ using a spectrophotometer (Beckman Coulter, Brea, CA). A 1 ug aliquot of total RNA was reverse transcribed using the RETROscript kit from Ambion (Austin, TX). The resultant cDNA (20 ng cDNA/sample in duplicate) was then subjected to quantitative polymerase chain reaction (qPCR) using standard target specific TaqMan gene expression assays for Rev-erb- $\alpha$ (Assay ID: Mm00441730_m1), HO-1 (Assay ID: Mm00516005_m1), peroxisome proliferator activated receptor gamma (PPAR $\gamma$ ) (Assay ID: Mm01184322_m1), PPAR $\gamma$ coactivator-1 alpha (PGC-1a) (Assay ID: Mm01208835_m1), and Bmal1 (Assay ID: Mm00500226_m1) and a real time PCR system (StepOne Plus Real-Time PCR System, Applied Biosystems, Foster City, CA). Relative quantitation of amplified cDNA targets were determined by the $\Delta \Delta \mathrm{CT}$ method using StepOne v2.1 software (Applied Biosystems).

\section{Statistical analysis}

A one-way analysis of variance (ANOVA) was utilized to detect the effects for diet (LFD vs. HFD) and CO treatment on gene expression. A repeated measures one-way ANOVA was utilized to detect differences in blood glucose levels during the IAGTT. Following a significant F ratio and inspection of interactions, Fisher's LSD post-hoc test was used to locate statistically significant differences between groups. Data are expressed as means \pm SEM, and the level of statistical significance was set at $\mathrm{p}<0.05$. For $\mathrm{mRNA}$ expression, means \pm SEM were expressed relative to the LFD group mean (\% LFD). Data was analyzed using StatView statistical software (SAS Institute Inc., Version 5.0, Cary, NC).

\section{Results}

\section{Effect of CO treatment on adiposity}

To assess the effects of a HFD and CO treatment on adiposity, we measured body weight and EWAT mass. As expected, a HFD produced a significant increase in body weight and EWAT mass compared to mice fed a LFD (Figures 1A and 1B). Following the 15 week dietary intervention, HFD mice were body weight-match-assigned to a CO treatment group or a control group (room air) and maintained on the HFD. In HFD mice. Treatment with CO ( $1 \mathrm{hr} /$ day) for did not significantly change body weight or EWAT mass (Figures 1A and 1B), indicating that $\mathrm{CO}$ does not reverse pre-existing diet-induced obesity.

\section{Effect of CO treatment on insulin action}

In vivo insulin action was determined by conducting IAGT tests
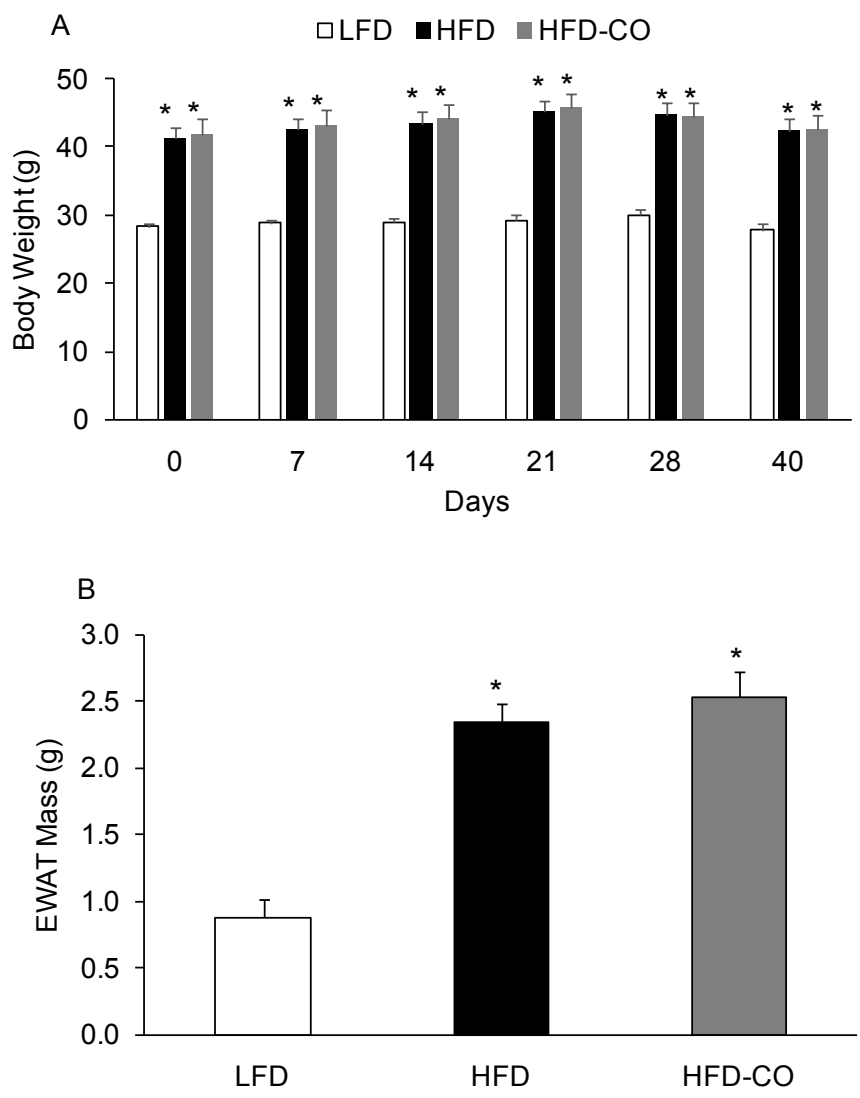

Figure 1. CO treatment does not reduce diet-induced obesity in mice. Body weights were assessed at various time points during $\mathrm{CO}$ treatment (A). EWAT mass was assessed at the end of the treatment period (B). *Denotes statistically significant differences from LFD group. $\mathrm{N}=6-7$ mice per group. 
that detect diet-induced insulin resistance at more physiologically relevant blood glucose levels than insulin tolerance tests Blood glucose values were higher during the IAGT test in mice fed a HFD compared to a LFD, indicating the presence of diet-induced insulin resistance (Figures 2A and 2B). In HFD mice treated with CO, blood glucose levels were similar during the IAGT test compared to HFD mice treated with room air (Figures $2 \mathrm{~A}$ and $2 \mathrm{~B}$ ), indicating that $\mathrm{CO}$ treatment does not improve insulin resistance in mice with pre-existing diet-induced obesity.

\section{Effect of CO treatment on HO-1 mRNA Expression}

Because CO treatment, whether administered by gas inhalation or $\mathrm{CO}$ releasing molecules, increases $\mathrm{HO}-1$ expression and activity $[8,17,20]$, we used HO-1 mRNA expression in EWAT as a positive control to demonstrate that our $\mathrm{CO}$ gas treatment regimen was effective in adipose tissue. As expected, treating mice with CO gas (250 ppm, 1 $\mathrm{hr} /$ day) for six weeks resulted in a significant increase in HO-1 mRNA expression in EWAT from mice fed a HFD (Figure 3).

\section{Effect of CO treatment on the expression of Rev-erb- $\alpha$ targets}

Rev-erb- $\alpha$ is a gas responsive transcriptional repressor that has been shown to regulate circadian rhythms, metabolism, and adiposity
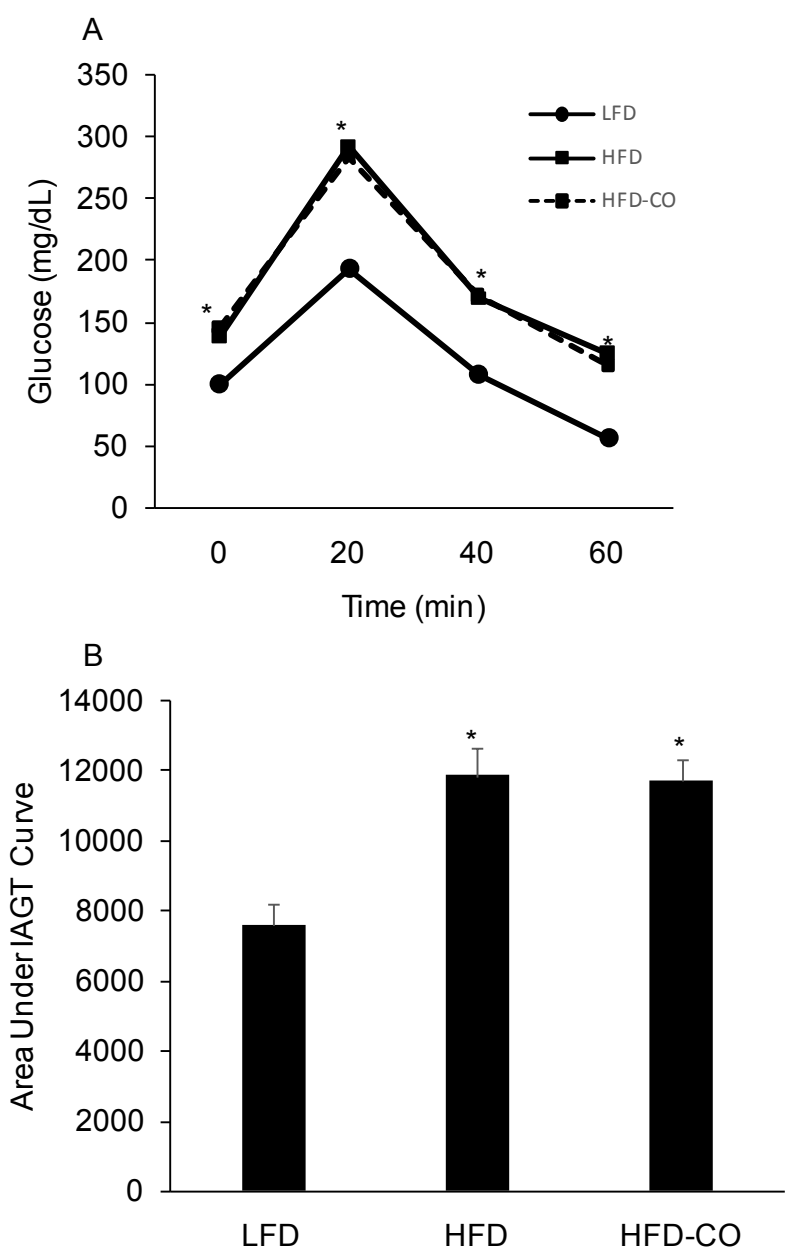

Figure 2. CO treatment does not improve insulin-assisted glucose tolerance (IAGT) in mice fed a HFD. Mice were simultaneously injected with $2.0 \mathrm{U} / \mathrm{Kg}$ insulin and 2.0 $\mathrm{g} / \mathrm{Kg}$ glucose and blood glucose values were assessed at baseline and 20, 40, and 60 min following the injection (Panels A) and the area under the IAGT curve was calculated (Panels B). *Denotes statistically significant difference from LFD group. $\mathrm{N}=6-7$ mice per group.

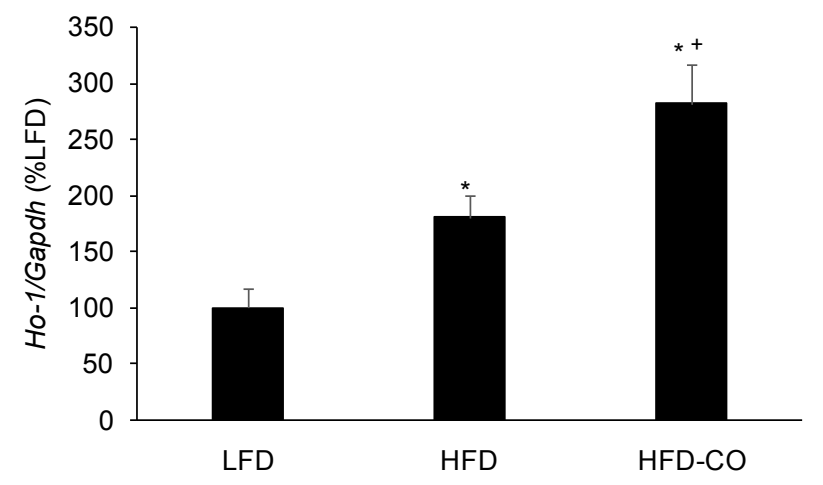

Figure 3. CO treatment increases HO-1 mRNA levels in adipose tissue from mice fed a HFD. The mRNA levels for HO-1 from EWAT of LFD, HFD and HFD-CO mice were quantified by real time PCR as described in Methods. *Denotes statistically significant difference from the LFD group. $\mathrm{N}=4-5$ mice per group.

$[10,13,14]$. Because CO is thought to bind Rev-erb and promote transcriptional repression [10], we examined the mRNA expression of Rev-erb- $\alpha$ targets in EWAT from mice with pre-existing diet-induced obesity that were treatment with $\mathrm{CO}$ for six weeks. CO treatment did not alter the expression of the Rev-erb- $\alpha$ targets Bmal1, Ppar $\gamma$, and Pgc- $1 \alpha$ (Figures 4A-4C). Since Rev-erb- $\alpha$ represses its own expression, we assessed its mRNA expression in response to CO treatment and observed no significant changes (Figure $4 \mathrm{~A}$ ). These finding indicate that in vivo $\mathrm{CO}$ treatment does not alter the expression of established Rev-erb- $\alpha$ targets in mice with established diet-induced obesity.

\section{Discussion}

The present study examined the effect of chronic CO treatment on adiposity, insulin action, and the expression of Rev-erb- $\alpha$ targets in mice with established diet-induced obesity. We observed no significant changes in adiposity as assessed by body weight and EWAT mass in HFD-fed mice that were treated with CO compared to HFD-fed mice that where treated with air. Further, chronic CO treatments did not improve HFD-induced insulin resistance as blood glucose values during IAGT test were almost identical between HFD-CO and control HFD-fed mice. Finally, the expression of Rev-erb- $\alpha$ targets were not altered in EWAT of mice that received daily $\mathrm{CO}$ treatment. However, CO treatment increased HO-1 mRNA levels in adipose tissue, thereby uncoupling the relationship between HO-1, insulin sensitivity, and weight loss [3].

$\mathrm{CO}$ is a product of HO-1 enzymatic activity and thought to mediate the improved insulin action and weight loss observed when the HO-1 gene is overexpressed [3-6]. In this context, the most interesting finding of the present study is the observation that $\mathrm{CO}$ treatment increased the expression of HO-1 mRNA without altering insulin action or adiposity. Our present observation is unique and different than studies demonstrating that increasing HO-1 expression by metalloporphyrin administration results in a reduction in body weight $[3,21,22]$. Importantly, it appears that the ability of metallophyrins to decrease adiposity and improve insulin sensitivity is dependent on HO- 1 induction because the HO- 1 inhibitor, stannous mesoporphyrin, abolished the metalloporphyrin-mediated decrease in body weight [3]. However, other studies support our lack of an effect of CO mediated increases in HO-1 mRNA expression on insulin action and obesity. For example, overexpression of HO-1 in adipose tissue does not alter HFDinduced obesity or insulin resistance in mice [23] and HO-1 expression was a strong predictor of metabolic disease in humans [24]. The present 

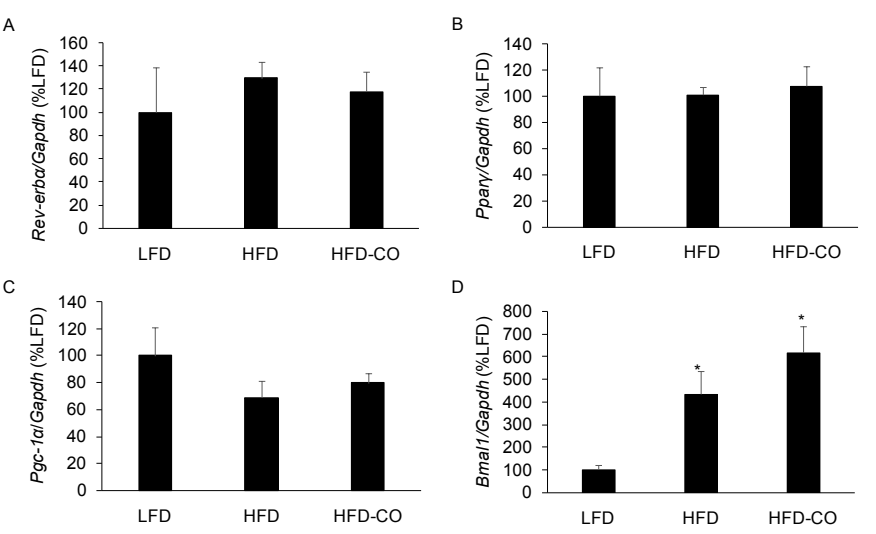

Figure 4. CO treatment does not alter the expression of Rev-erb- $\alpha$ and Rev-erb- $\alpha$ targets in adipose tissue from mice fed a HFD. The mRNA levels for Bmall (A), Ppar $\gamma(\mathrm{B})$, Pgc-1 $\alpha$ (C), and Rev-erb- $\alpha$ (D) from EWAT of LFD, HFD and HFD-CO mice were quantified by real time PCR as described in Methods. *Denotes statistically significant difference from the LFD group. $\mathrm{N}=5-7$ mice per group.

study provides additional evidence that inducing HO-1 expression, at least by $\mathrm{CO}$ inhalation, is not sufficient for improving insulin action or reducing adiposity.

Our results showing that chronic $\mathrm{CO}$ inhalation does not improve HFD-induced obesity and insulin resistant may be related to how CO was administered. Hosick et al. demonstrated that carbon monoxide releasing molecules promote weight loss and improve insulin action [8]. Although 10 weeks of CO inhalation appears to reduce body weight, this effect is transient and completely absence at 35 weeks [9]. Interestingly, the present results show no effect of approximately six weeks of daily $\mathrm{CO}$ inhalation (1 hour/day for 40 days) on body weight or insulin action in mice with established obesity. It is difficult to reconcile the differences between our findings and that of Hosick et al. [8,9]. Since some of the beneficial effects of $\mathrm{CO}$ are mediated by an increase in reactive oxygen species [25], this response may be abrogated in mice with established weight stable obesity because of the already high levels of ROS [26]. Finally, the lack of a CO effect in the present study and that of Hosick et al. [9] may be related to the delivery of the gas by inhalation rather than via CO releasing molecules [8], particularly since $\mathrm{CO}$ gas is primarily transported bound to hemoglobin and $\mathrm{CO}$ releasing molecules reach tissues independent of hemoglobin. However, we observed a significant increase in HO-1 expression in adipose tissue following the $\mathrm{CO}$ inhalation treatment indicating effective CO delivery to cells $[817,20]$, although we did not directly measure tissue $\mathrm{CO}$ content or assess markers for $\mathrm{CO}$ action in other tissues. Future work is needed to determine the mechanism for the different responses between $\mathrm{CO}$ delivered by inhalation compared to carbon monoxide releasing molecules.

The present study also tested the novel hypothesis that CO would alter Rev-erb- $\alpha$ dependent gene expression. Rev-erb- $\alpha$ is a nuclear receptor and thought to be a gas responsive transcription factor that regulates circadian rhythms and metabolism [10,13,14,27]. Recently, a Rev-erb agonist has been shown to promote weight loss and suppress PGC-1 $\alpha$ mRNA expression, an established target of Rev-erb- $\alpha$ [14]. Previous work demonstrated that E75, a Drosophila orthologue of human Rev-erb- $\alpha$, binds CO and NO [10]. Subsequent work in cultured HEK 293T and HepG2 cells confirmed that CO and NO bind Rev-erb- $\alpha$, however CO only had modest effects on the expression of Rev-erb- $\alpha$ targets compared to NO [27]. The present study clearly demonstrates that $\mathrm{CO}$ inhalation does not alter the expression of Rev- $e r b-\alpha$ targets in adipose tissue of obese mice. It is unlikely that the gas delivery method explains the ineffectiveness of $\mathrm{CO}$ treatment on the expression of Rev-erb- $\alpha$ targets because CO inhalation has been shown to stimulate PGC-1 $\alpha$ dependent gene expression in skeletal muscle and anti-inflammatory signaling in liver $[17,28]$. Furthermore, we observed an increase in HO-1 mRNA expression in adipose tissue in HFD-fed mice that were treated with $\mathrm{CO}$. However, it is possible that obese mice are resistant to $\mathrm{CO}$ action as we have observed a significant decline in insulin action and PGC-1 $1 \alpha$ in adipose tissue of lean mice that were treated with CO for 7 days (unpublished data).

\section{Conclusion}

We have shown that $\mathrm{CO}$ treatment does not reverse established diet-induced obesity and insulin resistance despite an increase in HO-1 mRNA levels. Furthermore, CO treatment does not alter the expression of Rev-erb- $\alpha$ targets or Rev-erb- $\alpha$ itself. Future studies examining the effects of $\mathrm{CO}$ releasing molecules on established weight-stable obesity and Rev-erb- $\alpha$ are warranted. Because NO binds Rev-erb- $\alpha$ with greater affinity than $\mathrm{CO}$, future studies that interrogate the effect of nitrate donors on adiposity and the expression of Rev-erb- $\alpha$ targets are needed.

\section{Authorship and contributorship}

THR is the principal investigator that designed and directed all aspects of the study. TB, RM, and BS all contributed to the manuscript by conducting experiments, analyzing data, and creating figures. TB and RM assisted in preparing the manuscript for submission.

\section{Funding information}

This work was supported by National Institutes of Health 1 R15 DK090722-01, a Skidmore College Opportunity Fund Grant and Skidmore College Summer Research Grant.

\section{Conflict of interest}

The authors declare that they have no financial or non-financial competing interests.

\section{References}

1. Ogden CL, Carroll MD, Flegal KM (2014) Prevalence of obesity in the United States. JAMA 312: 189-190. [Crossref]

2. American Diabetes Association (2013) Economic costs of diabetes in the U.S. in 2012. Diabetes Care 36: 1033-1046. [Crossref]

3. Li M, Kim DH, Tsenovoy PL, Peterson SJ, Rezzani R, et al. (2008) Treatment of obese diabetic mice with a heme oxygenase inducer reduces visceral and subcutaneous adiposity, increases adiponectin levels, and improves insulin sensitivity and glucose tolerance. Diabetes 57: 1526-1535. [Crossref]

4. Burgess A, Li M, Vanella L, Kim DH, Rezzani R, et al, (2010) Adipocyte heme oxygenase-1 induction attenuates metabolic syndrome in both male and female obese mice. Hypertension 56: 1124-1130. [Crossref]

5. Csongradi E, Docarmo JM, Dubinion JH, Vera T, Stec DE (2012) Chronic HO-1 induction with cobalt protoporphyrin (CoPP) treatment increases oxygen consumption, activity, heat production and lowers body weight in obese melanocortin-4 receptordeficient mice. Int J Obes (Lond) 36: 244-253. [Crossref]

6. Cao J, Peterson SJ, Sodhi K, Vanella L, Barbagallo I, et al. (2012) Heme oxygenase gene targeting to adipocytes attenuates adiposity and vascular dysfunction in mice fed a high-fat diet. Hypertension 60: 467-475. [Crossref]

7. Morse D, Pischke SE, Zhou Z, Davis RJ, Flavell RA, et al. (2003) Suppression of inflammatory cytokine production by carbon monoxide involves the JNK pathway and AP-1. J Biol Chem 278: 36993-36998. [Crossref]

8. Hosick PA, AlAmodi AA, Storm MV, Gousset MU, Pruett BE, et al. (2014) Chronic carbon monoxide treatment attenuates development of obesity and remodels adipocytes in mice fed a high-fat diet. Int J Obes (Lond) 38: 132-139. [Crossref] 
9. Hosick PA, Ahmed EK, Gousset MU, Granger JP, Stec DE (2014) Inhalation of carbon monoxide is ineffective as a long-term therapy to reduce obesity in mice fed a high fat diet. BMC Obes 1: 6. [Crossref]

10. Reinking J, Lam MM, Pardee K, Sampson HM, Liu S, et al. (2005) The Drosophila nuclear receptor e75 contains heme and is gas responsive. Cell 122: 195-207. [Crossref]

11. Harding HP, Lazar MA (1995) The monomer-binding orphan receptor Rev-Erb represses transcription as a dimer on a novel direct repeat. Mol Cell Biol 15: 47914802. [Crossref]

12. Zamir I, Harding HP, Atkins GB, Hörlein A, Glass CK, et al. (1996) A nuclear hormone receptor corepressor mediates transcriptional silencing by receptors with distinct repression domains. Mol Cell Biol 16: 5458-5465. [Crossref]

13. Duez H, Staels B (2009) Rev-erb-alpha: an integrator of circadian rhythms and metabolism. J Appl Physiol (1985) 107: 1972-1980. [Crossref]

14. Solt LA, Wang Y, Banerjee S, Hughes T, Kojetin DJ, et al. (2012) Regulation of circadian behaviour and metabolism by synthetic REV-ERB agonists. Nature 485: 6268. [Crossref]

15. Yin L, Wu N, Curtin JC, Qatanani M, Szwergold NR, et al. (2007) Rev-erbalpha, a heme sensor that coordinates metabolic and circadian pathways. Science 318: 17861789. [Crossref]

16. Raghuram S, Stayrook KR, Huang P, Rogers PM, Nosie AK, et al. (2007) Identification of heme as the ligand for the orphan nuclear receptors REV-ERBalpha and REVERBbeta. Nat Struct Mol Biol 14: 1207-1213. [Crossref]

17. Beckman JD, Belcher JD, Vineyard JV, Chen C, Nguyen J, et al. (2009) Inhaled carbon monoxide reduces leukocytosis in a murine model of sickle cell disease. Am J Physiol Heart Circ Physiol 297: H1243-1253. [Crossref]

18. Joe Y, Kim SK, Chen Y, Yang JW, Lee JH, et al. (2015) Tristetraprolin mediates antiinflammatory effects of carbon monoxide on lipopolysaccharide-induced acute lung injury. Am J Pathol 185: 2867-2874. [Crossref]
19. Reynolds TH 4th, Cinquino N, Anthony M, Phelps CB, Zachary Berk E (2009) Insulin resistance without elevated mammalian target of rapamycin complex 1 activity in muscles of mice fed a high-fat diet. J Appl Physiol (1985) 107: 1479-1485. [Crossref]

20. Piantadosi CA, Carraway MS, Babiker A, Suliman HB (2008) Heme oxygenase-1 regulates cardiac mitochondrial biogenesis via Nrf2-mediated transcriptional control of nuclear respiratory factor-1. Circ Res 103: 1232-1240. [Crossref]

21. Galbraith RA, Kappas A (1989) Regulation of food intake and body weight by cobalt porphyrins in animals. Proc Natl Acad Sci U S A 86: 7653-7657. [Crossref]

22. Galbraith RA, Kappas A(1990) Cobalt-protoporphyrin suppresses expression of genetic obesity in homozygous (fa/fa) Zucker rats. Pharmacology 41: 292-298. [Crossref]

23. Huang JY, Chiang MT, Chau LY (2013) Adipose overexpression of heme oxygenase- 1 does not protect against high fat diet-induced insulin resistance in mice. PLoS One 8: e55369. [Crossref]

24. Jais A, Einwallner E, Sharif O, Gossens K, Lu TT, et al. (2014) Heme oxygenase-1 drives metaflammation and insulin resistance in mouse and man. Cell 158: 25-40. [Crossref]

25. Zuckerbraun BS, Chin BY, Bilban M, d'Avila JC, Rao J, et al. (2007) Carbon monoxide signals via inhibition of cytochrome $\mathrm{c}$ oxidase and generation of mitochondrial reactive oxygen species. FASEB J 21: 1099-1106. [Crossref]

26. Furukawa S, Fujita T, Shimabukuro M, Iwaki M, Yamada Y, et al. (2004) Increased oxidative stress in obesity and its impact on metabolic syndrome. J Clin Invest 114: 1752-1761. [Crossref]

27. Pardee KI, Xu X, Reinking J, Schuetz A, Dong A, et al. (2009) The structural basis of gas-responsive transcription by the human nuclear hormone receptor REV-ERBbeta. PLoS Biol 7: e43. [Crossref]

28. Rhodes MA, Carraway MS, Piantadosi CA, Reynolds CM, Cherry AD, et al. (2009) Carbon monoxide, skeletal muscle oxidative stress, and mitochondrial biogenesis in humans. Am J Physiol Heart Circ Physiol 297: H392-399. [Crossref]

Copyright: $\odot 2016$ Brodsky T. This is an open-access article distributed under the terms of the Creative Commons Attribution License, which permits unrestricted use, distribution, and reproduction in any medium, provided the original author and source are credited. 